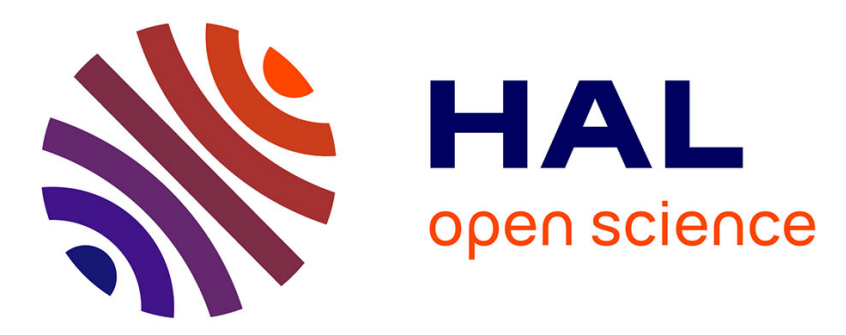

\title{
A study of teachers' views towards practical work in secondary schools in England and Wales
}

\author{
Ian Abrahams, Murat Sağlam
}

\section{To cite this version:}

Ian Abrahams, Murat Sağlam. A study of teachers' views towards practical work in secondary schools in England and Wales. International Journal of Science Education, 2010, 32 (06), pp.753768. 10.1080/09500690902777410 . hal-00582126

\section{HAL Id: hal-00582126 \\ https://hal.science/hal-00582126}

Submitted on 1 Apr 2011

HAL is a multi-disciplinary open access archive for the deposit and dissemination of scientific research documents, whether they are published or not. The documents may come from teaching and research institutions in France or abroad, or from public or private research centers.
L'archive ouverte pluridisciplinaire HAL, est destinée au dépôt et à la diffusion de documents scientifiques de niveau recherche, publiés ou non, émanant des établissements d'enseignement et de recherche français ou étrangers, des laboratoires publics ou privés. 


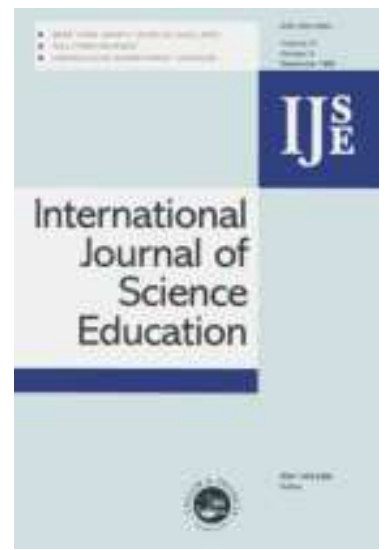

\section{A study of teachers' views towards practical work in secondary schools in England and Wales}

\begin{tabular}{|r|l|}
\hline Journal: & International Journal of Science Education \\
\hline Manuscript ID: & TSED-2008-0258.R2 \\
\hline Manuscript Type: & Research Paper \\
\hline Keywords: & laboratory work, practical work, secondary school, teacher beliefs \\
\hline Keywords (user): & views towards practical work \\
\hline
\end{tabular}

\section{scholarONE" \\ Manuscript Central}




\begin{abstract}
Many teachers view practical work as an essential feature of science education. This study examined whether there had been any changes in the relative importance of the aims science teachers assign to the use of practical work, across the full secondary age range (11-18), since the last such national survey undertaken by Kerr (1963).
\end{abstract}

A stratified sample of representative schools was used in which 912 teachers were sent a questionnaire on their views towards the use of practical work in science with a total of 393 responses (42.5 percent) being received. The coefficient of concordance (Kendall, 1955) of the various rankings and their significance were calculated, as too were the z-scores.

The findings suggest that whilst there have been substantial changes in teachers' views about the use of practical work at Key Stages 4 and 5 (age 15-18) there have been no substantial changes at Key Stage 3 (age 11-14). Furthermore, the results are remarkably similar across subject specialism, teacher gender, and years of teaching experience although this paper will only focus on subject specialism. It appears that changes to the assessment criteria, notably the introduction of Science Investigation (Sc1) at Key Stage 4, and a growing desire amongst educational policy makers to improve the image of science, have had an effect on how those in the teaching profession perceive the value and aims of practical work particularly at Key Stages 4 and 5 . 


\section{Introduction}

In many countries practical work is an essential feature of the teaching and learning of science and considerable time and money is spent on teaching science through practical work and it is therefore important to be clear about the aims of practical work. In an important study in England and Wales, Kerr (1963) identified ten aims of practical work (Table 1) and subsequent national and international studies into the aims of practical work are broadly in agreement with the aims suggested by Kerr (Johnstone and Al-Shuaili, 2001).

As in many countries, much has changed in the educational system in England and Wales in the forty-five years since Kerr (1963) reported the findings of the first published survey of teachers' views towards the aims of practical work across the full 11-18 age range in secondary schools following a traditional grammar type curriculum. Indeed, the tripartite system of grammar, secondary modern and technical schools, in which only a minority of pupils, educated in grammar schools, followed an academically orientated science curriculum whilst the majority received a more general, vocationally based, science education in secondary modern and technical schools, no longer exists. Furthermore, the introduction of widespread comprehensive education in the mid 1960s gave rise to the development of a range of new approaches to the teaching of science such as Nuffield Secondary Science in the late 1960's with its emphasis on the use of practical work to develop scientific methods of thought and its aim to enable pupils to find out through investigation (Gott \& Duggan, 1995) and Warwick Process Science in the 1980's with its emphasis on the use of practical work as a means of developing transferable process skills such as observing and interpreting (Screen, 1998, 1986). The importance of these changes, or any 
changes to teachers working environments, is, in terms of the evolutionary model developed by Johnson, Monk and Swain, (1998), that they lead to changes in teachers' practice and opinion. If this model is correct then future changes to the way science is taught and/or assessed have the potential to change the way in which teachers view the role of practical work and, as a consequence, use it. The introduction of a National Curriculum in 1989, which saw science become a 'core' subject, has meant that teachers are now required to teach science to all pupils throughout the compulsory phase of their secondary school education (age 11-16). A possible consequence of this is that teachers now find themselves trying to maintain pupils' interest in a subject that, prior to the introduction of a National Curriculum, many would have chosen to drop at the end of Key Stage 3 (see Table 2 and the note at the end of the paper for additional explanation of Key Stages). It might therefore be expected that the potential affective value of practical work might be seen by teachers as more important than might otherwise have been before science became a core subject as a result of the evolutionary pressures (Johnson, Monk \& Swain, 1998) that its introduction have created in the educational environment in which science teachers operate.

Therefore whilst the Third International Mathematics and Science Survey (TIMSS, 1999) has shown performance in science, and most notably in practical work (Kind, 1999), has improved amongst pupils in England and Wales over the last decade it is important to consider whether these improvements reflect any changes in the relative importance of the aims science teachers assign to the use of practical work. The findings of this study may be of interest to researchers, policy makers and science 
educators in the countries where there have been substantial changes in the structure of science education.

\section{The need for an enquiry}

Following a grant by the Gulbenkian Foundation in 1960 Kerr undertook the first extensive survey to investigate the nature and purpose of practical work within the framework of grammar school science teaching in England and Wales. The study involved 151 schools, $56 \%$ boys' schools, $26 \%$ girls' schools and $18 \%$ co-educational, all of whom followed a common 'grammar type' curriculum and involved a total of 701 science teachers.

Despite the fact that some of the teachers appeared to be responding to the questions without those responses reflecting their actual beliefs or practices (Abrahams \& Millar, 2008), the study did provide the first large-scale insight into practicing teachers' views as to the nature and purpose of school practical work in England and Wales. The findings, which involved the teachers arranging ten suggested aims (purposes) for practical work in order of perceived importance, are summarised in Table 1.

\section{TABLE 1 GOES HERE}

In conclusion Kerr (1963) reported that whilst most science teachers placed strong emphasis on individual practical work this work had become relatively "inflexible, repetitive, outmoded and often inadequately integrated with the theory... In all science subjects, there was plenty of practical work being done but it was not well 
integrated with the theory and it was unlikely to achieve the unique educational value often claimed [by educational theorists] for it" (pp. 95-96).

However, despite all of the changes that have occurred over the last four decades there have only been two subsequent published national studies of teachers' views about the aims of practical work in England and Wales (Lynch \& Ndyetabura, 1983 and Wilkinson \& Ward, 1997 carried out two similar studies in Australia). Whilst the first of these (Thompson, 1975), focused solely on teachers' views about practical work at Key Stage 5 (age 17-18) the second (Beatty, 1980) only considered views about practical work amongst teachers of pupils within part of Key Stage 3 (age 11-13). Furthermore, both of these subsequent studies used an expanded questionnaire in which teachers were required to rank twenty aims of practical work - developed by Thompson (1975) - that, whist subsuming the original ten aims of practical work used by Kerr (1963), prevented any direct comparison of either of their results with that initial study. The expanded questionnaire differed from the original in that the additional aims were designed to accommodate potential changes to teachers' aims for using practical work that, it was felt, might have arisen from the introduction of Nuffield Science.

As this study was specifically designed to examine whether there had been any changes to teachers' views about the aims of practical work across the entire secondary school age range and across all three traditional sciences, it was felt more appropriate to use the original ten aims devised by Kerr (1963) so as to enable a direct comparison with Kerr's broader findings to be made. 


\section{Plan of enquiry}

\section{The questionnaire}

Whilst there are advantages and disadvantages to the use of postal surveys (Bailey, 1994; Cohen, Manion \& Morrison, 2007; Robson, 1993) the decision to undertake a national study meant that a postal questionnaire survey was the most cost-effective and convenient method for collecting a relatively large amount of data from across a wide geographical area. Despite these advantages it is important to recognise two main reasons why questionnaire surveys can lead to fallacious results (Belson, 1986; Cohen, Manion \& Morrison, 2007; Verma \& Mallick, 1999) and appropriate steps were taken to prevent, or at least reduce, the impact that these might have on the findings of the study. The first reason, although not restricted solely to questionnaires, is that there is no way of ascertaining, short of receiving back all of the questionnaires, whether the returned questionnaires are truly representative of the entire sample who received them. To reduce the potential that the responses received were not representative of the sample as a whole this study sought to maximise the response rate through the use of phased follow-up letters (Bailey, 1994; Cohen, Manion \& Morrison, 2007; Hoinville \& Jowell, 1978; Verma \& Mallick, 1999) achieving a final response rate of 42.5 percent. Additionally a check was made on how representative the returned questionnaires were by comparing the proportion of questionnaires sent out to those returned by school type (Table 3) which showed there to be no major discrepancy.

The second reason that a questionnaire survey, and in particular a postal questionnaire, can lead to fallacious results is that the researcher is unable to ensure that the questions are fully understood and/or answered in the way stipulated in the 
written instructions (Belson, 1986). Whilst it was hoped that asking teachers to rank the same ten aims as those piloted and used successfully by Kerr (1963) would reduce the likelihood of teachers failing to understand what was required of them the views of a focus group of science teachers $(\mathrm{N}=7)$ regarding the clarity of the questions was also sought. As a result of feedback from the focus group it was deemed necessary to make two changes to the original Kerr (1963) questionnaire to make it easier for current teachers to understand what was being asked of them and it is to these changes that we now turn.

The first of these changes was that whilst Kerr had asked teachers to respond to the questionnaire in terms of three Year group categories 1-2, 3-5 and $6^{\text {th }}$ Form the current study opted to use the three Key Stages from the National Curriculum that, it was felt by the focus group, would be more easily recognised and better understood by current teachers. Furthermore, it was felt that in England and Wales Key Stages provide natural transition points in the teaching of science at which teacher's views about the use of practical work might be more likely, if they were to change at all, to do so. Table 2 shows the changes to the way pupils are categorised by Year group in both studies.

\section{TABLE 2 GOES HERE}

Secondly, the focus group felt that because pupils were, at the time of this study, assessed on their performance of a practical investigation ( $\mathrm{Sc} 1)$, and this contributes to their grade in the General Certificate of Secondary Education (GCSE) - a public examination taken at age 16 - the aim "To fit the requirements of practical 
examination regulations" (Kerr 1963 p. 27) needed to be modified so as to make explicit that this also included the potential aim of practical work as a means of preparing pupils for the assessed practical investigation ( $\mathrm{Sc1}$ ). The modified aim, used in this study, was "To prepare pupils for assessed practical work - including Sc1 investigations".

The instructions in the questionnaire asked teachers to rank the aims, in each of the three Key Stages, in order of their perceived importance by putting ' 1 ' in the appropriate column to the right of the aim which was viewed as being most important '2' alongside the next, ' 3 ' alongside the third and so on to ' 10 ' opposite the least applicable with each number from one to ten to be used one only in each column. The full questionnaire was piloted by the focus group with science teachers $(\mathrm{N}=15)$ in their respective schools with no difficulties being reported.

\section{The sample}

Whilst the Kerr (1963) study was limited to teachers within 151 secondary schools following a traditional grammar type curriculum, this study used a stratified sample of 304 representative schools, selected from across the state and independent (privately funded) sectors, with three questionnaires being sent to the head of science at each school. A total of 912 questionnaires were sent out with 388 being returned (42.5\%) of which 25 were excluded from analysis for various reasons. The frequency distributions of the questionnaires sent out and those returned are listed in Table 3. There was no statistically significant difference between the frequency distributions (chi-square $=2.408, d f=3$, not significant). This indicates that the responses closely reflected the stratified sample from which they were drawn. 


\section{TABLE 3 GOES HERE}

\section{Method of analysis}

This study examines whether there have been any changes in the importance teachers attached to the aims of practical work, across the entire secondary age range and across all three traditional sciences, since the Kerr (1963) study in England and Wales. Since there are three Key Stages and three science subjects in the study, there are nine comparisons to make with the Kerr study.

A frequently used method to compare ranked data involves the calculation of the sum of ranks for each item rank. The sums are then put into rank order, and the differences between rank orders are shown diagrammatically (for examples see Beatty \& Woolnough, 1982; Saglam \& Millar, 2006; Thompson 1975; Whitfield, 1979). Figure 1 shows such a comparison between Key Stage 3 chemistry teachers in the Kerr study and the current study. The figure also presents the mean of the sum of ranks for each aim, on which the rank order is based, since the number of the chemistry teachers at Key Stage 3 was different in each study.

\section{FIGURE 1 GOES HERE}

An initial conclusion, from a preliminary analysis of Figure 1, might be that there had been no change in the importance Key Stage 3 chemistry teachers attached to Aim 5 between both studies as it was ranked $10^{\text {th }}$ in both studies. Likewise the two-place difference between the ranks of Aim 8 suggests that there has been a change in the importance Key Stage 3 chemistry teachers ascribe to that aim having risen from 
being ranked $5^{\text {th }}$ to $3^{\text {rd }}$ in the rank order of aims. However, if the analysis is based on the means of the sum of ranks, instead of simply the rank orders, we find that the preliminary conclusion obscured the fact that whilst there was a small difference $(0.09$ points) between the means of the sum of ranks of Aim 8 there was a much greater difference (1.95 points) between the means of the sum of ranks of Aim 5.

In order to better examine the scope of any difference in teachers' views it was decided to use the means of the sum of ranks, instead of the more basic rank orders, to analyse any change in the importance teachers attached to the aims of practical work. However, there remains one problem with using the means of the sum of ranks in any such analysis. This is that although, irrespective of the sample size, the average of the means of the sum of ranks remains 5.5 the standard deviation in both studies will differ. For example in Figure 1 it can be seen that whilst the sum of ranks in both studies is 5.5 the standard deviation is 2.15 for the Kerr study and 1.61 for the current study. In order to compare the means of the sum of ranks they need first to be expressed on the same scale and to achieve this it is necessary to convert each mean into a z-score. Howitt and Cramer (2000) make clear that 'the number of standard deviations is a universal scale of measurement' and that 'the $z$-score is nothing other than the number of standard deviations a particular score lies above or below the mean of the set of scores' (p. 46, italics in the original). For example, in order to calculate the z-score of Aim 9 in the current study (Figure 1), we simply subtract 5.5 from 2.74 , and then divide by the standard deviation of 1.61 , which is -1.714 . The magnitude of the z-score indicates that the mean of the sum of ranks of Aim 9 in the current study is 1.714 standard deviations away from the mean of the set of scores, and the minus sign indicates that it is below the mean of the set of scores. It is 
important to note that by converting the means of the sum of ranks into z-scores we do not change their distribution but rather express them in standard deviations from the average.

In the discussions above it was assumed that the sums of ranks were representing the Key Stage 3 chemistry teachers' rank orders. Yet such an assumption requires there to be sufficient agreement between the teachers' rank orders and to ascertain whether this was the case a measure of the degree to which the teachers agree was needed. Kendall (1955) developed the coefficient of concordance (W) as a means of calculating the degree of agreement between various rank orders. The coefficient of concordance ranges from zero, when there is no agreement between the various rank orders, to +1 when there is full agreement. The statistical significance of the coefficient of concordance can be calculated using a Chi Squared test provided there are seven or more judges doing the ranking (Howell, 1997). For example the coefficient of concordance for Key Stage 3 chemistry teachers in the current study was 0.28 . This is statistically significant at the $1 \%$ level, suggesting that there was sufficient agreement between the Key Stage 3 chemistry teachers' rank orders to enable the sums of ranks to be considered as representative of all of the Key Stage 3 chemistry teachers' rank orders.

Having discussed the degree of agreement between rank orders and the use of z-scores in comparing the means of the sum of ranks we now illustrate the use of z-scores in our analysis of the data using a set of z-scores from the study. [The full list of z-scores can be obtained from the authors electronically]. Table 4 shows the z-scores for Key Stage 5 chemistry teachers in the Kerr study and the current study, and the differences 
between them. The magnitude of each difference provides a measure of the relative change in the z-score of each specific aim. The negative signs in Table 4 indicate that the z-scores of these aims have decreased relative to their value in the first study. For example, the change in z-score for Aim 2 was - 1.997, indicating that compared with the Kerr study, the chemistry teachers in the current study gave less importance to Aim 2. On the other hand, the change in z-score for Aim 10 was 1.869, indicates that compared with the Kerr study, the chemistry teachers in the current study gave more importance to Aim 10.

\section{TABLE 4 GOES HERE}

We have categorised changes in z-score of between 0 and 0.333 as 'small'; 0.333 and 0.666 as 'limited'; 0.666 and 0.999 as 'moderate' and those of more than 0.999 as 'substantial'. Whilst recognising that the boundaries of such categories are, as with the assessment of the data using diagrammatic methods, essentially arbitrary we feel that they provide a useful method of comparing results from both studies.

\section{Results}

Results from the study will be presented in two sections. The first section will deal with the overall results of the study whilst the second section will discuss the changes in the importance teachers attached to the aims of practical work, by Key Stage, since the Kerr (1963) study. 


\section{Overall Results}

Kendall's coefficient of concordance (W) was calculated to evaluate the agreement within the nine comparison groups. Of the nine coefficients of concordance all were found to be statistically significant at the $1 \%$ level. This suggests that the means of the sum of ranks of each group can be accepted as being representative of the importance that each group of science teachers attaches to the ten suggested aims of practical work. One notable finding was that the level of agreement in each Key Stage, and across all three science subjects, was very similar: although the level of agreement had its highest value amongst teachers at Key Stage 3. Therefore although there was agreement among science teachers about the aims of practical work, across the three Key Stages, it appears that those teaching at Key Stages 4 and 5 were less sure about those aims than teachers teaching at Key Stage 3. One possible line of future study might therefore be to investigate whether there is a similar pattern of the level of agreement in other countries, and the reason(s) for such a pattern.

\section{Change in the aims of practical work}

In this paper we will only discuss substantial changes in z-scores: where a change is said to be substantial if its magnitude is greater than or equal to 1 . Table 5 shows all substantial changes in the z-score that were found.

\section{TABLE 5 GOES HERE}




\section{Changes at Key Stage 3}

As there were no substantial changes in the z-scores relating to teachers' views about the aims of practical work at Key Stage 3 since the original study by Kerr (1963) there are no results for Key Stage 3 in Table 5. Interestingly the most important purpose of practical work at Key Stage 3, across all science subjects, remains, as it was forty-five years ago, to arouse and maintain interest in the subject (Aim 9) whilst the least important purpose of practical work continues to be that of preparing pupils for assessed practical work (Aim 5) - which, in the current study, explicitly included Sc1 investigations.

\section{Changes at Key Stage 4}

The largest changes in z-scores observed in this study occurred at Key Stage 4 with regards Aim 5, which relates to preparing pupils for assessed practical work including Sc1 investigations. Although Kerr (1963) acknowledges the possible role of practical work in preparing pupils for practical examinations there was also a recognition that it was too much to expect more than a few teachers to admit to using practical work to this end. Perhaps those teaching science in the early twenty-first century are more realistic and/or pragmatic about the influence of practical examinations on the aims and values of practical work.

As Kerr (1963) notes Aims 1 and 2 refer to 'the possible effects of practical work on one's subsequent thinking and behaviour' (p. 22). The substantial negative changes in z-scores relating to these aims at Key Stage 4 (and 5) suggests that science teachers today see these aims as being less important for older pupils - although the importance of these aims for pupils at Key Stage 3 remained unchanged - than did the 
science teachers in the Kerr study. Comments written by some of the teachers on the questionnaires suggested that it was not that these aims - which relate to basic scientific skills - suddenly ceased to have any importance in Key Stages 4 and 5 but rather that they saw the need to prioritise different aims at different Key Stages. A frequent point made by teachers was that although the emphasis on encouraging accurate observation and careful recording along with the promotion of simple, common-sense, scientific methods of thought was seen as relatively important at Key Stage 3 - to enable pupils to begin effectively engaging with practical work - these were seen as being less important, relatively speaking, than other aims at Key Stages 4 and 5 whose importance had increased. The exception to this was that in terms of Aim 1 there was no substantial change in the z-score associated with physics teachers' views towards the importance of encouraging accurate observation and careful recording. Interestingly, although only three physics teachers commented on this point, all three emphasised the importance of accurate observation and the careful recording of data if a high mark was to be achieved in the Sc1 assessed practical.

Evidently whilst teachers are aware that the National Curriculum considers observation and scientific thinking as important practical skills to be taught at Key Stage 4 - they clearly have an expectation that pupils would have developed sufficient proficiency in these skills during Key Stage 3 to enable teachers to prioritise other aims of practical work in Key Stages 4 and 5.

The most substantial increase in z-score at Key Stage 4 relates to the use of practical work 'to prepare pupils for assessed practical work - including Sc1 investigations' although, as can be seen from Table 5, there is no substantial change at Key Stage 5. 
Whilst few teachers made any comment on this specific aim those that did mentioned the pressure of trying to ensure that their pupils did well in the Sc1 assessment, as this contributed towards their total GCSE examination grade.

Aims 9 and 10 are concerned with the 'possible affects on one's general attitude to science by increasing the desire to learn and the level of understanding' (Kerr, $1963 \mathrm{p}$. 22). Whilst there was a substantial rise in terms of the z-scores associated with physics teachers' views towards Aims 9 and 10, and a similar substantial rise amongst chemistry teachers for Aim 10, no substantial change in z-scores was found amongst biology teachers for either of these aims. However, that said, it must be emphasised that these two aims were, as at Key Stage 3 , ranked $1^{\text {st }}$ and $2^{\text {nd }}$ by all teachers and the observed substantial increase in their z-score, amongst chemistry and physics teachers, simply indicates that those teachers saw them as being even more important than at Key Stage 3. The emphasis teachers place on the potential affective value of practical work both at Key Stage 3 and, more importantly at Key Stage 4, might help to explain the reported (Joint Council for Qualifications, 2008) rise in the number of pupils now opting to take one or more science subjects in the post-compulsory Key Stage 5. It is unclear why there was no substantial rise in z-scores amongst Key Stage 4 biology teachers regarding these two aims. One possible explanation might be that as the number of pupils taking biology at Key Stage 5 has been increasing year on year (Osborne, Simon \& Collins, 2003) there was less pressure on biology teachers to change their views towards the use of practical work as they were evidently already effectively generating a sufficiently positive attitude towards biology amongst their pupils. Conversely the teachers of physics, which is seen as the least popular science, as measured by the number of pupils who go on to study the subject at Key Stage 5 


\section{Changes at Key Stage 5}

Similar to the changes that occurred at Key Stage 4 there were substantial falls in the importance teachers assigned to Aims 1 and 2 and, unlike at Key Stage 4, there were no exceptions. One of the physics teachers, one who had commented on the importance of encouraging accurate observation and careful recording at Key Stage 3, made the further point, about making accurate observations and careful recordings, that "If they don't know how to do it by the time they're doing 'A' level [Key Stage 5] they shouldn't be doing 'A' level physics."

At Key stage 5 there was also a substantial fall amongst biology and physics teachers' views about the use of practical work to develop manipulative skills although this was not the case amongst chemistry teachers. Whilst only one chemistry teacher commented on this aim, so it can only be seen as anecdotal, it was interesting in so far as they claimed that "A level [Key Stage 5] chemistry requires higher order manipulative skills and it's vital that we teach these". Clearly if this is the case, and we have no evidence to support or refute this claim, it would offer a possible explanation as to why chemistry teachers continued to see this particular aim as being relatively important. Aims 9 and 10 saw the most pronounced rise in teachers' views about their importance and, unlike at Key Stage 4, this was across all the science 
subjects. Those teachers that commented upon this, and again there were only a few, spoke of a need to make science real and relevant in order to maintain an interest in what was a much more conceptually demanding subject than it had been at Key Stage 4. Although there has been a substantial rise in the z-scores relating to these two aims - they are now ranked $4^{\text {th }}$ and $3^{\text {rd }}$ respectively - it is unclear as to the extent to which this reflects a desire, on the part of the science teachers, to encourage Key Stage 5 pupils towards studying a science degree at university as educational policy makers and advisors (Department for Education and Employment 1996; Royal Society, 2006) suggest is vital for the UK economy.

\section{Conclusions and Implications for Teaching and Research}

The aim of this study was to see whether there had been any changes in the relative importance of the aims science teachers assign to the use of practical work, across the full secondary age range (11-18), since the last published national survey of teachers' views about practical work undertaken by Kerr (1963). One important finding has been the fact that despite the many changes in the educational system in England and Wales during the last forty five years - including the introduction of a National Curriculum - teachers' views about the aims of practical work for pupils in Key Stage 3 have remained virtually unchanged. Indeed, our findings replicate those of Beatty and Woolnough (1982) who, twenty-six years ago, noted similarly, with regards KS3 (in fact only Years 7 and 8) that ' $[\mathrm{t}]$ here is no evidence of a dramatic change in the reasons that teachers give for doing practical work since 1962, despite all the curriculum innovations in the succeeding period'. We believe that this stability, and the high degree of concordance amongst teachers regarding the aims for the use of practical work at this Key Stage in both this study and that of Kerr (1963), is a 
reflection of the fact that there is less perceived competition between the aims. Certainly the fact that these pupils do not have to undertake public examinations involving practical work means that it is relatively unproblematic for teachers to rank the aim of preparing pupils for assessed practical work - including Sc1 investigations - very low whilst their desire to portray science as a fun and exciting 'hands-on' subject (Abrahams, 2007) means that many teachers will rank its potential affective value i.e. to arouse and maintain interest in the subject highly.

In terms of the evolutionary model developed by Johnson, Monk and Swain (1998) '[c]hanges to the working environment of teachers through curricula reform, inservice provision and increased resources will lead to changes in pedagogy which in turn will alter opinions' (p. 1322). However, despite the introduction of the National Curriculum - which has clearly changed the working environment - this study has found no substantial change in current teachers' aims regarding the use of practical work at Key Stage 3 compared to those obtained by Kerr (1963) over forty years ago. One possible way of understanding this is to propose that it is not, as Johnson, Monk and Swain (1998) suggest, that changes in the working environment lead to changes in pedagogy and subsequently teachers' opinions - including those on the aims and/or use of practical work - but that changes in the working environment have the potential to lead to changes in pedagogy if those changes generate pressure on (or removed it from) teachers. We would argue that the absence of any substantial change to the z-scores associated with teachers' views about the use of practical work at Key Stage 3 suggests that the National Curriculum did not generate any pressure on teachers to change their pedagogy and/or opinions, regarding practical work, in order for them to continue to operate successfully within their new working environment. 
The most substantial change in teachers' aims for practical work (Table 5) occurred at Key Stage 4 and it would appear to reflect the introduction of the Sc1 investigations and the associated pressure on biology, chemistry and physics teachers that this has generated in terms of needing to prepare pupils for assessed practical work. Indeed Donnelly, Buchan, Jenkins, Laws and Welford (1996), in a detailed study of the 'Scientific Enquiry' component of the English National Curriculum (Attainment target Sc1), found that extended, and more open-ended, investigative practical tasks were, in fact, rarely being used to teach pupils about specific aspects of scientific enquiry might have been, but almost entirely to assess their ability to conduct an empirical enquiry 'scientifically' - something that they would be required to do as part of their public examinations. It would seem, therefore, that an unintended consequence for educational policy makers of the introduction of Attainment Target Sc1 may have been that teachers' views about the use of practical work were influenced by government led changes to the assessment procedures (that generate pressure on teachers) - and that this was particularly pronounced at KS4.

Following the recent decision by educational policy makers to remove Sc1 as a means of assessment - and, as such, the pressure on teachers that was associated with it - we would predict, and this would be an interesting area for further research, that the importance of using practical work 'to prepare pupils for assessed practical work including Sc1 investigations' would return to a position at, or very close to, the bottom of teachers' aims for using practical work at Key Stage 4.

Whilst many science teachers at Key Stages 4 and 5 substantially decreased the status of the aims 'to encourage accurate observation and careful recording', 'to promote 
simple, common-sense, scientific methods of thought' and 'to develop manipulative skills', we do not believe that this necessarily means that they no longer see these as important in an objective sense. Rather, we would claim, that such changes are more likely to reflect the fact that teachers recognise, as a result of pressures in the educational environment, that different aims are more important, relative to other aims, at different stages within secondary education if their teaching is to be effective. Indeed it might be expected that if these aims were effectively met, for example, in Key Stage 3 - when their importance is ranked highly - then their relative importance at Key Stages 4 and 5 might be expected to drop as has been found in this study.

We suggest that helping those undertaking initial teacher training to recognise the way in which practicing teachers' views about the relative importance of the different aims for practical work change at different Key Stages could enable them to better reflect on their own reasons for using practical work at a particular Key Stage.

An interesting finding to emerge from our use of $\mathrm{z}$-scores was the fact that some seemingly identical changes in rank order, such as the change in the rank order of Aim 9 by the biology and physics teachers at Key Stage 4, were in fact not identical in magnitude when considered in terms of changes in their respective z-scores. Indeed, in the above example, only in the case of physics teachers was the change in z-score found to be substantial: a finding that would not have emerged had the analysis relied solely upon the change in the rank order of a particular aim. For this reason we suggest that in future studies z-scores should be used instead of rank orders as a means of comparing sets of ranking data. 


\section{Note}

The use of the term 'Key Stage' is peculiar to the UK. Key Stage 3 relates to the first three years of secondary school education (ages 11-14). Key Stage 4 corresponds to the fourth and fifth years of secondary school education (pupils aged 15-16): the completion of which marks the end of compulsory education in the UK. Key Stage 5 corresponds to the two years of post-compulsory secondary school education (pupils aged 17-18).

\section{References}

Abrahams, I.Z. (2007). Practical work: It's better than writing but does it motivate? Education in Science 224, 10-11.

Abrahams, I. \& Millar, R. (2008). Does practical work really work? A study of the effectiveness of practical work as a teaching and learning method in school science. International Journal of Science Education. 30 (14), 1945-1969.

Bailey, K. D. (1994). Methods of social research. New York: The Free Press. Beatty, J.W. (1980). School science, its organisation and practical work in the 11-13 age range. Unpublished MSc dissertation. Oxford: University of Oxford.

Beatty, J. W. \& Woolnough, B. E. (1982). Practical work in 11-13 science: The context, type and aims of current practice. British Educational Research Journal, 8 (1), 23-30.

Belson, W. A. (1986). Validity in survey research. Aldershot: Gower.

Cohen, L., Manion, L \& Morrison, K. (2007). Research methods in education. Abingdon: Routledge.

Department for Education and Employment (1996). Labour market and skill trends. London: Department for Education and Employment. 
Donnelly, J., Buchan, A., Jenkins, E., Laws, P. \& Welford, G. (1996). Investigations by order. Policy, curriculum and science teachers' work under the education reform act. Nafferton, UK: Studies in Education Ltd.

Gott, R. \& Duggan, S. (1995). Investigative work in the science curriculum. Buckingham: Open University Press.

Hoinville, G. \& Jowell, R. (Eds.) (1978). Survey research practice. London: Heineman Educational Books.

Howell, D.C. (1997). Statistical methods for psychology, $4^{\text {th }}$ ed. London: International Thomson Publishing Europe.

Howitt, D. and Cramer, D. (2000). An introduction to statistics in psychology: A complete guide for students. Essex: Pearson Education Ltd.

Johnson, S., Monk, M. \& Swain, J. (1998). Teacher development and change in Asia and Africa: An evolutionary perspective. Paper presented at Teaching Effectiveness and Teacher Development in the New Century. Hong Kong.

Johnstone, A.H. and Al-Shuaili, A. (2001). Learning in the laboratory; some thoughts from the literature. University Chemistry Education, 5 (2), 42-51.

Joint Council for Qualifications (JCQ) (2008). National provisional GCE A and AS level results - June 2008. http://www.jcq.org.uk/attachments/ published/984/ JCQ\% 20A-Level\%20Results\%202008.pdf. Accessed December 11, 2008.

Kendall, M. G. (1955). Rank correlation methods. London: Griffin.

Kerr, J. F. (1963). Practical work in school science. Leicester: Leicester University Press.

Kind, P.M. (1999). TIMSS performance assessment - a cross national comparison of practical work. In J. Leach \& A.C. Paulsen (Eds.) Practical work in science education - recent research studies. Dordrecht: Kluwer Academic publishers. 
Lynch, P. \& Ndyetabura, V.L. (1983). Practical work in schools: An examination of teachers' stated aims and the influence of practical work according to students. Journal of Research in Science Teaching, 20, 663-671.

Osborne, J., Simon, S. \& Collins, S. (2003). Attitudes towards science: A review of the literature and its implications. International Journal of Science Education, 25 (9), 1049-1079.

Robson, C. (1993). Real world research. Oxford: Blackwell.

Royal Society (2006). A degree of concern. http://royalsociety.org/document.asp

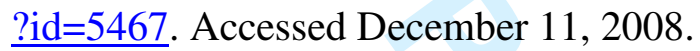

Saglam, M. \& Millar, R. (2006). Upper high school students' understanding of electromagnetism. International Journal of Science Education, 28 (5), 543-566.

Screen, P.A. (1986). The Warwick process science project. School Science Review, 72 (260), 17-24.

Screen, P.A. (1998). A case for a process approach: The Warwick experience. Physics Education, 23, 146-149.

Swain, J., Monk, M., \& Johnson, S. (1999). A comparative study of attitudes to the aims of practical work in science education in Egypt, Korea and the UK. International Journal of Science Education, 21 (12), 1311-1324.

Third International Mathematics and Science Study (TIMSS) (1999). International Science Report. isc.bc.edu/timss 1999. html. Accessed May 2007.

Thompson, J. J. (Ed.). (1975). Practical work in sixthform science. Oxford: Department of Educational Studies, University of Oxford.

Verma, G. K. \& Mallick, K. (1999). Researching education: Perspectives and techniques. London: Falmer Press. 
1

2

3

4

5

6

7

8

9

10

11

12

13

14

15

16

17

18

19

20

21

22

23

24

25

26

27

28

29

30

31

32

33

34

35

36

37

38

39

40

41

42

43

44

45

46

47

48

49

50

51

52

53

54

55

56

57

58

59

60

Whitefield, R. C. (1979). Educational research and science teaching. School Science Review, 60 (212), 411-430.

Wilkinson, J. \& Ward, M. (1997). A comparative study of students' and their teachers' perceptions of laboratory work in secondary schools, Research in Science Education, 27, 599-610. 
Table 1 Teachers' ten suggested aims (purposes) for practical work in order of perceived importance (From Kerr 1963 p. 27)

\begin{tabular}{|c|c|c|c|c|}
\hline \multicolumn{5}{|c|}{ Pooled Order of Importance of Aims of Practical Work } \\
\hline & & \multicolumn{3}{|c|}{ Physics teachers } \\
\hline & & $\begin{array}{l}\text { Years 1-2 } \\
\text { KS3 }\end{array}$ & $\begin{array}{l}\text { Years 3-5 } \\
\text { KS4 }\end{array}$ & $6^{\text {th }}$ Form \\
\hline 1 & $\begin{array}{l}\text { To encourage accurate observation and } \\
\text { careful recording }\end{array}$ & 5 & 4 & 1 \\
\hline 2 & $\begin{array}{l}\text { To promote simple, common-sense, } \\
\text { scientific methods of thought }\end{array}$ & 4 & 3 & 4 \\
\hline 3 & To develop manipulative skills & 7 & 8 & 6 \\
\hline 4 & To give training in problem solving & 9 & 9 & 8 \\
\hline 5 & To fit the requirements of practical & 10 & 10 & 10 \\
\hline & examination regulations & & & \\
\hline 6 & To elucidate the theoretical work so as to & 6 & 2 & 2 \\
\hline & aid comprehension & & & \\
\hline 7 & To verify facts and principle already & 8 & 7 & 5 \\
\hline & taught & & & \\
\hline 8 & $\begin{array}{l}\text { To be an integral part of the process of } \\
\text { finding facts by investigation and arriving }\end{array}$ & 3 & 1 & 3 \\
\hline & at principles & & & \\
\hline 9 & To arouse and maintain interest in the & 1 & 5 & 9 \\
\hline
\end{tabular}


10 To make physical phenomena more real

2

6

7 through actual experience 
Table 2. A comparison of the age ranges used in both studies

\begin{tabular}{llll}
\hline Year ranges of pupils & Youngest range & Middle range & Oldest range \\
\hline Kerr & Years 1-2 & Years 3-5 & $6^{\text {th }}$ Form \\
& Ages 11-13 & Ages 14-16 & Ages 17 - 18 \\
& & & \\
Abrahams and Saglam & Years 1-3 (KS3) & Years 4-5 (KS4) & $6^{\text {th }}$ Form (KS5) \\
& Ages 11- 14 & Ages 15 - 16 & Ages 17 - 18 \\
\hline
\end{tabular}


Table 3. Number of the questionnaires by school type

\begin{tabular}{lcccc}
\hline Teachers & $\begin{array}{c}\text { Comprehensive } \\
\text { school teachers }\end{array}$ & Grammar & Independent & Specialist \\
& school teachers & school teachers & school teachers \\
\hline Total sample $(\mathrm{N}=912)$ & 546 & 90 & 138 & 138 \\
Analysed sample $(\mathrm{N}=363)$ & 206 & 46 & 57 & 54 \\
\hline
\end{tabular}


Table 4. Change in the z-scores for Key Stage 5 chemistry teachers

\begin{tabular}{lccc}
\hline Aim & The Kerr study & The current study & Change in z-score \\
\hline 1 & -1.466 & -0.105 & -1.362 \\
2 & -0.455 & 1.542 & -1.997 \\
3 & 0.092 & 0.390 & -0.297 \\
4 & 0.357 & 0.993 & -0.636 \\
5 & 0.372 & 0.851 & -0.479 \\
6 & -1.312 & -1.717 & 0.405 \\
7 & 0.147 & -0.258 & 0.405 \\
8 & -0.565 & -1.004 & 0.438 \\
9 & 1.801 & 0.148 & 1.653 \\
10 & 1.029 & -0.840 & 1.869 \\
\hline
\end{tabular}

URL: http://mc.manuscriptcentral.com/tsed Email: ijse_editor@hotmail.co.uk 
Table 5. Substantial changes in z-scores

\begin{tabular}{|c|c|c|c|c|c|}
\hline \multirow{2}{*}{\multicolumn{3}{|c|}{ Aims of practical work }} & \multicolumn{3}{|c|}{ Science Subject } \\
\hline & & & \multirow{2}{*}{$\begin{array}{r}\text { Biology } \\
-1.613\end{array}$} & \multirow{2}{*}{$\begin{array}{r}\text { Chemistry } \\
-1.130\end{array}$} & \multirow{2}{*}{ Physics } \\
\hline 1 & To encourage accurate observation & KS4 & & & \\
\hline & and careful recording. & KS5 & -1.743 & -1.362 & -1.704 \\
\hline \multirow[t]{2}{*}{2} & To promote simple, common-sense, & $K S 4$ & -1.571 & -1.462 & -1.299 \\
\hline & scientific methods of thought. & $K S 5$ & -1.506 & -1.997 & -1.389 \\
\hline 3 & To develop manipulative skills. & KS5 & -1.712 & & -1.419 \\
\hline 5 & To prepare pupils for assessed & KS4 & 2.084 & 1.880 & 2.169 \\
\hline & practical work - including Sc1 & & & & \\
\hline & investigations. & & & & \\
\hline \multirow[t]{2}{*}{9} & To arouse and maintain interest in & $K S 4$ & & & 1.152 \\
\hline & the subject. & $K S 5$ & 1.492 & 1.653 & 1.839 \\
\hline \multirow[t]{3}{*}{10} & To make biological, chemical and & $K S 4$ & & 1.230 & 1.021 \\
\hline & physical phenomena more real & KS5 & 1.282 & 1.869 & 1.058 \\
\hline & through actual experience. & & & & \\
\hline
\end{tabular}

Note: $\mathrm{KS}$ is for Key Stage 
Figure 1. A comparison between Key Stage 3 chemistry teachers in the Kerr study and the current study

\begin{tabular}{|c|c|c|c|c|}
\hline \multirow[b]{2}{*}{$\begin{array}{c}\text { Rank order of } \\
\text { aims }\end{array}$} & \multicolumn{2}{|c|}{ The Kerr study } & \multicolumn{2}{|c|}{ The current study } \\
\hline & Aim & $\begin{array}{c}\text { Mean of the sum } \\
\text { of ranks }\end{array}$ & Aim & $\begin{array}{c}\text { Mean of the sum } \\
\text { of ranks }\end{array}$ \\
\hline 1 & 9 & 2.45 & 9 & 2.74 \\
\hline 2 & 1 & 3.74 & 10 & 3.22 \\
\hline 3 & 10 & 3.79 & 8 & 5.12 \\
\hline 4 & 2 & 4.05 & 1 & 5.20 \\
\hline 5 & 8 & 5.03 & 6 & 5.39 \\
\hline 6 & 6 & 5.57 & 2 & 5.62 \\
\hline 7 & 3 & 5.83 & 3 & 5.99 \\
\hline 8 & 7 & 6.72 & 7 & 6.51 \\
\hline 9 & 4 & 7.58 & 4 & 7.42 \\
\hline 10 & 5 & 9.74 & 5 & 7.79 \\
\hline
\end{tabular}

